NBER WORKING PAPER SERIES

\title{
HISTORY VS. EXPECTATIONS
}

\author{
Paul Krugman
}

Working Paper No. 2971

NATIONAL BUREAU OF ECONOMIC RESEARCH

1050 Massachusetts Avenue

Cambridge, MA 02138

May 1989

This paper is part of NBER's research program in International Studies. Any opinions expressed are those of the authors not those of the National Bureau of Economic Research. 
NBER Working Paper $\# 2971$

May 1989

HISTORY VS. EXPECTATIONS

$\underline{\text { ABSTRACT }}$

In models with external economies, there are often two or more long run equilibria. Which equilibrium is chosen? Much of the literature presumes that "history" sets initial conditions which determine the outcome, but an alternative view stresses the role of "expectations", i.e. of self-fulfilling prophecy. This paper uses a simple trade model with both external economies and adjustment costs to show how the parameters of the economy determine the relative importance of history and expectations in determining equilibrium.

Paul Krugman

Department of Economics

MIT

50 Memorial Drive

Cambridge, MA 02139 
In recent years there has been increasing interest in economic models in which there are positive external economies in production; these models have been seen as a way to formulate rigorously a number of heterodox challenges to standard economic doctrine. Ethier (1982a,1982b) has provided a new, streamlined exposition of Graham's (1923) argument that external economies may make the pattern of international trade arbitrary and the gains from trade ambiguous, and has also shown that monopolistic competition in intermediate goods may lead to de facto external economies in production of final goods. Romer $(1986 \mathrm{a}, 1986 \mathrm{~b})$ has shown that external economies may remove the traditional distinction between factor accumulation and technical change as sources of growth, and has also shown that an Ethier-like formulation can rationalize Allyn Young's (1928) vision of cumulative growth driven by increasing returns. Murphy, Shleifer, and Vishny (1988) have shown how market-size effects can in effect create external economies among firms investing in industrialization, and have used this insight to offer a rigorous formulation of Rosenstein-Rodan's (1943) "Big Push" theory of economic development. In my own work $(1981,1987)$ I have used external economies to formulate an "uneven development" model in which the division of the world into rich and poor nations takes place endogenously, and a model in which a variety of heterodox views are justified by a framework in which patterns of specialization generated by historical accident get "locked in" through learning effects. 
A key element in many of these models is the possibility of meaningful multiple equilibrla in the presence of external economies. The point is obvious: when there are external economies, it will often happen that the return to committing resources to some activity is higher, the greater the resources committed. Thus in Murphy, Shleifer, and Vishny (1988), the return to investment is higher the rate of investment; in krugman (1987) the rate of learning in a sector is larger the larger the sector; and so on. In the emerging literature on increasing returns and externalities, multiple equilibria are not a nuisance but a central part of the story.

Once one has multiple equilibria, however, there is an obvious question: which equilibrium actually gets established? Although few have emphasized this point, there is a broad division into two camps in both the traditional literature and the recent models on this question. On one side is the belief that the choice among multiple equilibria is essentially resolved by history: that past events set the preconditions that drive the economy to one or another steady state. In the traditional literature this view is the preponderant one; indeed, as I will emphasize later there is à strong tradition arguing that history matters precisely because of increasing returns. On the other side, however, is the view that the key determinant of choice of equilibrium is expectations: that there is a decisive element of self-fulfilling prophecy.

The purpose of this paper is twofold: to point out the importance of the 
history vs, expectations distinction, and to shed light on the issue by presenting an illustrative model in which the relative importance of the past and the expected future can be seen to depend on objective parameters of the economy. The model also has some technically interesting features, showing somewhat surprisingly that a role for self-fulfilling prohecies emerges when the deterministic dynamic system would exhibit oscillatory behavior. While the model developed here is very simple and fairly special, I hope that its properties will turn out to be useful guides to studying more elaborate and realistic models in the future.

\section{History vs. expectations in the literature}

The idea of external economies goes back to Marshall, and it was Marshall who formulated the concept of backward-looking dynamics that underlies most informal and some formal treatments of the determination of long-run equilibrium with externalities. In Marshall's dynamics, factors of production shift gradually toward those activities in which they earn the highest current rate of return. If there are several possible equilibria in which factor returns would be equalized across activities, then Marshallian dynamics tell us that the outcome depends on the initial conditions: history, as well as tastes, technology, and factor endowments, matters.

The idea that the main effect of multiple equilibria is to give a crucial 
role to history appears in many of the classic arguments for including increasing returns and external economies in economic analysis. Myrdal (1957), for example, saw as the key failing of standard analysis its neglect of "circular causation", whereby divergences in initial conditions tend to grow over time. Kaldor (1972), in denouncing the "irrelevance of equilibrium economics", argued that the ahistorical nature of standard economic models arises precisely from their neglect of increasing returns. David (1985), in his analysis of how technologies get locked in by external economies. emphasized the role of historical accident in determining long run outcomes.

The dynamic process by which history comes to determine the choice of equilibrium is only implicit in this traditional literature. There is, however, also a formal literature in which dynamics are formulated in such a way that history is decisive. In the fairly extensive literature on trade with external economies, of which Ethier (1982a) and Panagariya (1986) are notable recent examples, there is usually a stability analysis in which Marshallian dynamics are used; these imply that the eventual choice of equilibrium depends on the starting point. In the stochastic analysis of choice of location and technique by Arthur (1986) it is presumed that successive arrivals on the scene decide where to locate on the basis of the choices of previous arrivals: thus history, as embodied in the (random) sequence of arrivals, determines the ultimate outcome. In Krugman (1981) the dynamics of capital accumulation insure that a region that starts with a slightly larger capital stock 
eventually ends up with a dominant industrial position, while in Krugman (1987) a trade model with learning is specified in such a way that any existing pattern of comparative advantage is reinforced over time, so that the current state of the economy determines its future.

The central role of history in determining which of several long-run equilibria emerges seems intuitive, and one would expect some role for history to emerge in most reasonable models. Yet the dynamics that underlie history-based models - dynamics that are, at base, Marshallian - - are ad hoc. And there is a crucial problem with this ad hockery that calls the role of initial conditions at least partly into question. Marshall assumed that resources move gradually in response to differences in current earnings. However, if resources move only gradually, it must be because it is costly for them to move. And if it is costly to move, then owners of resources will be interested not only in the current return on those resources but on expected returns in the future. In the presence of some kind of externality, however, future returns depend on the factor allocation decisions of other people -. which also depend on their expectations of future earnings. Thus there is at least potentially a possibility of self-fulfilling prophecy. Perhaps if everyone thinks that the economy will end up in equilibrium 1, then it will; but if they believed instead that it would end up in equilibrium 2, that would happen instead. In this case expectations rather than history play the decisive role. 
The classic expectations-cum-multiple equilibria story in the traditional literature is the "Big Push" doctrine of Rosenstein-Rodan (1943). In this story the willingness of firms to invest depends on their expectation that other firms will invest, so that the task of development policy is to create convergent expectations around high investment. A clean formalization of this story has been set forth by Murphy, Shleifer, and Vishny (1988); in this formalization the externality comes from the interaction of increasing returns and market-size effects. The result is a case of multiple equilibria in which the outcome is entirely a matter of self-fulfilling prophecy.

Expectation-driven multiple equilibria have also made their appearance in both industrial organization and macroeconomics. In industrial organization they arise in the context of adoption of a new technology, where network externalities mean that the individual desirability of adoption depends on what others do. Thus Farell and Saloner (1986), in a model of technology adoption, find that for some parameter values there are multiple equilibria, each of which could be a self-fulfilling prophecy. In macroeconomics, expectations-driven multiple equilibria have received the greatest attention in models of economies with search, including Diamond and Fudenberg (1987) and Howitt and McAfee (1988), where the desirability of participating in market activity depends on the likelihood of making trades. which in turn depends on how many others choose to participate.

The distinction between history and expectations as determinants of the 
eventual outcome is an important one. Both a world in which history matters and a world of self-fulfilling expectations are different from the standard competitive view of the world, but they are also significantly different from each other. Obviously, also, there must be cases in which both are relevant. Yet in the recent theoretical literature models have tended to be structured in such a way that either history or expectations matters, but not both. To take two examples: In Murphy, Shleifer, and Vishny (1987), which is a fully specified model, there is simply no room for history. On the other hand, in Krugman (1987), which is a little less careful about the intertemporal aspect but could be made more so, there is no room for expectations. Yet in the real world, we would expect there to be circumstances in which initial conditions determine the outcome, and others in which expectations may be decisive. But what are these circumstances?

Our next step is clearly to develop a dynamic economic model in which both history and expectations could matter, so that we can explicitly look at their respective roles.

\section{A simple model with multiple equilibria}

There are many externality models with multiple equilibria; it does not matter too much which we choose to examine. For the purposes of this paper I will choose a model that is well-known in the international trade literature. 
that of a nation engaging in trade that has external economies in one sector. This model is convenient because in its static version it is the subject of a long tradition, including Graham (1923), Matthews(1949), Chacoliades (1978), and Ethier (1982a); thus the surprising dynamic results reported below cannot be attributed to any exoticism of the underlying model. It should be apparent as we proceed, however, that similar results would obtain in a model of choice of location, as analyzed by Arthur (1986), in a model of choice of technology, as discussed by David (1985), or in any of a variety of external economy settings. Indeed, the results are very similar to (but much simpler than) those obtained in the analysis of search equilibrium by Diamond and Fudenberg (1987).

We consider, then, a one-factor economy. This economy is able to produce two goods: C, a good produced with constant returns, and $\mathrm{X}$, a good whose production is subject to an externality. Specifically, we assume that the larger the labor force engaged in $X$ production, the higher is labor productivity in that sector:

$$
\pi=\pi\left(\mathrm{L}_{\mathrm{X}}\right)
$$

This economy is assumed to be able to sell both $\mathrm{C}$ and $\mathrm{X}$ at fixed prices 
on world markets ${ }^{1}$. By choosing units of goods and labor, we can normalize so that one unit of labor produces one unit of $C$, and the value of that unit is one. So the wage rate in the $C$ sector is unity.

In the $\mathrm{X}$ sector, productivity depends on industry employment. Since the economies of scale are external, however, each firm treats labor productivity as constant, and the wage rate must therefore equal the average product:

$$
w=\pi\left(L_{X}\right)
$$

Given the normalization, $w$ is the wage rate in $\mathrm{X}$ relative to that in $\mathrm{C}$. To make life interesting, we assume $\pi(0)<1$ and $\pi(\bar{L})>1$, where $\bar{L}$ is the economy's total labor supply. That is, the wage rate in the $\mathrm{X}$-sector would be lower than in the $C$-sector if nobody were employed in $X$, but would be higher if everyone were employed there.

The existence of multiple equilibria is apparent. If nobody is employed ${ }^{1}$ Much of the literature on this model is concerned with the two-country equilibrium when neither country is small; it is well understood that the extreme specialization I derive here need not happen when world prices are endogenous. However, the dynamic analysis would of course be harder in the two-country case, so I restrict myself to small-country analysis here. 
in $X$, a worker considering producing $X$ would find that she would receive a lower wage than she receives producing $C$; so there is an equilibrium in which the economy is specialized in the production of $C$. On the other hand, if everyone is employed in the $X$ sector, a worker considering producing $C$ would find that this would involve a wage cut; so specialization in $X$ is also an equilibrium.

Which equilibrium does the economy go to? In expositions of this kind of model, one often appeals to a quasi-dynamic story of the kind illustrated in Figure 1. The figure shows on its horizontal axis the quantity of labor employed in the $X$ sector, which can range between 0 and $\dot{L}$, while on its vertical axis it shows the relative wage $w$. We suppose that the economy starts with some initial allocation of labor between the two sectors, and that labor moves toward the sector that offer the higher wage. The result is illustrated by the arrows. If the labor force in $\mathrm{X}$ is initially larger than the level $\mathrm{L}_{\mathrm{X}}^{*}$ at which $w=1$, then the $X$ sector will snowball until the economy is specialized in $X$; if it is initially smaller than $L_{X}^{*}$, the $X$ sector will unravel and the economy will specialize in $C$. Thus history, which determines the initial conditions, determines the ultimate outcome.

This is not a bad story, as a first cut. Indeed, the usefulness of this kind of heuristic approach to dynamics for thinking about models is so great 
that I would not propose abandoning it ${ }^{2}$. It should be apprent, however, that there are problems with using it here. Essentially the question is why labor should adjust slowly. Suppose first that labor can in fact move costlessly between the $X$ and $C$ sectors. Then in that case there is no reason why the initial distribution of labor should matter. Whatever the initial position, all workers will move to the sector that they expect to yield the higher wage - which is the sector that they expect all the other workers to move to. Thus in the absence of some cost of shifting labor either equilibrium can be obtained as a self-fulfilling prophecy, whatever the initial position.

To make the initial position matter, then, it is necessary to introduce some cost of adjustment in shifting labor between sectors. As soon as we do this, however, the decision of a worker to shift from $C$ to $X$ or vice versa becomes an investment decision, which depends not only on the current wage differential but on expected future wage rates as well. But these future wage rates depend depend on the decisions of other workers; if everyone expects many workers to move from $C$ to $X$ over time, this will increase the attractiveness of moving from $C$ to $X$ even if there is no immediate effect on

${ }^{2}$ See, for example, the use of Marshallian stability analysis by Neary (1978a), where a number of previously confused issues are neatly disposed of using this device. 
relative wage rates. In other words, one cannot have dynamics without expectations -- and once one has expectations playing a role, there is in this kind of model the possibility of self-fulfilling prophecy.

Does this mean that the traditional view that history is crucial for determining equilibrium is completely wrong? Is it always possible to reach either equilibrium if everyone expects it? The answer is no -- but to see this it is necessary to formulate the dynamics of the model explicitly.

\section{Making the model dynamic ${ }^{3}$}

${ }^{3}$ This dynamization of the external economy model is closely related to the dynamic model developed by Matsuyama (1988); in particular, the surprising dynamics illustrated in Figure 3 were first noted by Matsuyama in the context of his model. There are some technical differences: his model derives its dynamics from an overlapping-generations framework in which there is an intertemporal distortion as well as an externality. However, the main difference here is in. the questions asked. A subsequent extension (Matsuycarna 1989), written subsequent to presentation of a first draft of this paper: approaches the same questions asked here in the context of a more general model and with more elaborate techniques. 
To make the model explicitly dynamic, I follow Mussa (1978) by making the cost of shifting labor a function of the rate at which labor is moved between sectors. The simplest and most convenient functional form for this "moving cost" is quadratic; thus I assume that the national income of the economy at a point of time is

$$
Y=\pi\left(\mathrm{L}_{X}\right) \mathrm{L}_{X}+\left(\overline{\mathrm{L}}-\mathrm{L}_{\mathrm{X}}\right)-(1 / 2 \gamma)\left(\mathrm{L}_{\mathrm{X}}\right)^{2}
$$

where $\gamma$ is an inverse index of the cost of adjustment (so that $\gamma$ will turn out to be a measure of the speed of adjustment)

We suppose that individuals are able to borrow or lend freely on world markets at a given world interest rate $r$. Thus their objective is to maximize the present value of output,

$$
H=\int_{0}^{\infty} Y e^{-r t} d t
$$

If the economy were run by a social planner who could internalize the increasing returns to scale present in $X$ production, she would maximize (4) taking account of the dependence of productivity on the allocation of resources. Since the economy actually consists of individuals who do not internalize the externality, however, they take $\pi$ as given at each point in time. The market outcome may most easily be described as follows: labor moves 
at a rate determined by the equality of marginal moving costs and a shadow price that represents the difference in private value between having a unit of labor in the $\mathrm{X}$ sector and in the $\mathrm{Y}$ sector:

$$
I_{X}=\gamma q
$$

where $q$ is the shadow price placed on the "asset" of having a unit of labor in the $\mathrm{X}$ rather than the $\mathrm{C}$ sector, defined as

$$
\mathrm{q}(t)=\int_{t}^{\infty}(\pi-1) \mathrm{e}^{-r(\tau-t)} \mathrm{d} \tau
$$

. The rate of return on this "asset" must equal $r$ :

$$
r q=(\pi-1)+\dot{q}
$$

where $\pi-1$ is the difference in current earnings between labor in the $X$ and $C$ sectors, and $q$ is the rate of capital gains on the shadow asset. Equation (7) may be rearranged to give a dynamic equation for $q$ :

$$
\dot{q}=r q-\pi\left(L_{X}\right)+1
$$

Equations (5) and (8) define a dynamic system in $I_{X}, q$ space. The 
qualitative laws of motion of this system are shown by the small arrows in Figure 2. Whenever $\mathrm{q}$ is positive, $\mathrm{L}_{\mathrm{X}}$ is rising; whenever it is negative $\mathrm{L}_{\mathrm{X}}$ is falling. The upward-sloping line $q=0$ shows points where $q$ equals the capitalized value of a constant wage differential at the current rate. A higher value of $q$ can result only if $q$ is expected to rise, a lower value only if $q$ is expected to fall. These lines cross at $q=0, L_{X}=L_{X}^{*}$.

There are, of course, two possible long run equilibria of this model. At one, illustrated by $E_{C}$, the economy specializes completely in the production of $C$; at the other, $E_{X}$, the economy specializes in $X$. At each equilibrium $q$ equals the present value of the difference between what workers actually earn and what an individual worker would earn if she decided to produce the other good indefinitely.

We now ask what paths can lead to these equilibria, consistent with the laws of motion. Given the qualitative laws of motion shown in Figure 2 , it is clearly possible to draw paths leading to the two equilibria that form the S-shaped locus shown in the figure. The right half of the $S$ represents a path that leads to $E_{X}$, the left half a path that leads to $E_{C}$.

If the paths to the two equilibria did in fact look like those in Figure 2, the dynamic behavior of the model would be clear. Suppose we are given an initial allocation of labor between the two sectors. Then the initial value of $q$ must be set at the unique value that puts the economy on the S-shaped curve. From that point on the economy would simply obey the dynamics, converging to 
one or the other long run equilibrium. If $L_{x}>L_{x}^{*}$ initially, then the economy would gradually move to $E_{X}$; if $L_{X}<L_{X}^{*}$ initially, the economy would gradually converge to $\mathrm{E}_{\mathrm{C}}$. Thus the dynamics illustrated in Figure 2 confirm the ad hoc dynamic analysis that is commonly used to think about these models, and that was illustrated in Figure 1: resources move gradually toward whichever sector offers the higher current wage rate. Adding an explicit description of the decision to reallocate resources and of the implied role of expectations does not change much.

The paths shown in Figure 2 are not, however, the only possible ones consistent with the qualitative laws of motion. Inspecting the figure again, we see that instead of a monotonic approach to each long run equilibrium, the economy might follow a spiral. This leads to the artistically remarkable Figure 3: the equilibrium paths consist of two interlocking spirals that wind outward from the center of the figure and eventually separate to head for the two long-run equilibria. A look at the figure will confirm that these paths do indeed obey the laws of motion indicated by the small arrows. We may also confirm that the two spirals never cross one another simply by observing that there is a unique path from any point; since the two paths end up in different places, thay must not have any points in common.

Before turning to the economic interpretation of Figure 3, we had better confirm that both Figure 2 and Figure 3 are possible descriptions of equilibrium paths, and find out under what circumstances each description 
prevails.

\section{S-curve vs. spirals}

At this point it is necessary to place some more structure on the model. The simplest structure is a linear one: we suppose that the function $\pi\left(L_{X}\right)$ takes the particular form

$$
\pi=1+\beta\left(\mathrm{L}_{\mathrm{X}}-\mathrm{L}_{\mathrm{X}}^{*}\right)
$$

The system defined by (5) and (8) then constitutes a pair of linear differential equations.

A useful way to think about the paths shown in Figures 2 and 3 is to define $t=0$ as the time when the economy reaches either one of the long run equilibria. The possible paths to these equilibria are then traced out by working backwards in time.

The roots of the system defined by (5) and (8) are

$$
\rho=\left[r \pm\left(r^{2}-4 \beta \gamma\right)^{1 / 2}\right] / 2
$$

Thus there are two qualitative cases. If $r^{2}>4 \beta \gamma$, then there are two real positive roots. Then the system is unstable and must steadily diverge from 
$q=0, L_{X}=\frac{\grave{k}}{L_{X}}$. (Alternatively, if we run backwards in time the system is stable and converges steadily to $q=0, L_{X}=L_{X}^{*}$ ). On the other hand, if $r^{2}<4 \beta \gamma$ there are two complex roots with positive real parts. The system is unstable, but diverges from the center in expanding oscillations. (Running backwards in time, we trace out a path that converges in damped oscillations).

These two cases correspond to the pictures we have drawn in Figures 2 and 3. If the roots are real, the possible paths to the equilibria form the simple S-curve in Figure 2; if they are complex, they form the interlocking spirals of Figure $3 .^{4}$

What is the economic meaning of the case illustrated in Figure 3 ? First of all, we note that the spirals define a range of values of $L_{X}$, from $L_{X}^{C}$ to $\mathrm{L}_{\mathrm{X}}^{\mathrm{X}}$, from which either long-run equilibrium can be reached. Which one is

${ }^{4}$ It may at first appear that there could be paths that diverge from the unstable equilibrium and reach one or the other steady state after a finite number of oscillations; this would eliminate the correspondence between existence of the overlap defined below and complex roots. However, in a linear model such paths can be ruled out. One way to see this is to note that with real roots there can be at most one reversal of the direction of motion of each variable, and any paths more complicated than those drawn in Figure 2 would violate this if extended beyond the steady state. 
reached depends on expectations -- that is, for any initial position in that range there exists at least one set of self-fulfilling expectations leading to either long run outcome. In particular, there are the simple paths defined by the outer arms of the two spirals that lead most rapidly to either long run position. So the case of complex roots, which correponds to Figure 3, is also the case in which over some range expectations rather than history are decisive. It may be useful to have a shorthand way of referring to the range of $\mathrm{L}_{X}$ from which either equilibrium can be reached; I will refer to it as the overlap.

The surprising aspect of the results is that inside the overlap there may be more than one set of expectations that leads to each equilibrium. If people expect a direct path to $\mathrm{E}_{\mathrm{X}}$, that will happen; but for some values of $\mathrm{L}_{\mathrm{X}}$, there are also self-fulfilling cyclical paths. Indeed, as $L_{X}$ gets close to $L_{X}^{*}$, there get to be an infinite number of possible paths in each direction. Thus the possible dynamics are surprisingly complex.

It may be useful to offer an intuition behind these cyclical paths. Imagine a slightly different model, in which there is a small constant cost of adjustment and time is divided into discrete periods. Now suppose we propose an equilibrium in which all labor alternately is employed in the $\mathrm{X}$ sector and in the $C$ sector. Can this pointless oscillation be an equilibrium? on reflection it should be apparent that as long as adjustment costs are low enough it can. Everyone wants to work in the same sector as everyone else; if 
they believe that everyone else will switch sectors in alternate periods, they will do the same, validating these beliefs. The cyclical paths shown if Figure 3 reflect a similar kind of pointless but nonetheless potentially self-validating oscillation.

The possibility of cyclical paths should not be overemphasized, however, because in fact the possible dynamics within the range of the overlap are even more complex than Figure 3 suggests. The reason is the possibility of random jumps to the convergent paths. Once we have several possible deterministic paths, there is no reason to rule out stochastic paths that jump to one or another of the deterministic paths with some possibly time-varying probability. For example, consider the following example: suppose that initially $L_{X}<I_{X}^{*}$, and $q=0$. Since the current wage rate is higher in the $C$ sector when $\mathrm{L}_{X}<\mathrm{L}_{X}^{*}$, on a deterministic path we would have to have $\mathrm{q}$ rising at that point. However, we can instead postulate a stochastic equilibrium in which there is a constant probability that $q$ will suddenly jump up to the upper arm of the spiral leading to $E_{X}$ ' with this probability exactly high enough to yield an expected rate of change of $q$ that compensates for the lower wage. The result is then that $L_{X}$ reamins constant until at some random instant it suddenly begins to rise. The economic interpretation is that wages are higher in the $C$ sector, but that labor does not move into that sector because everyone expects that at some uncertain future date everyone else will start moving into production of $\mathrm{X}$. Even though there is no particular reason to 
believe this, for any $L_{X}$ in the relevant range there is a consistent set of beliefs that will yield this result. A large number of such stochastic stories can be constructed; most of them seem fairly silly, but there is nothing in the model per se to rule them out.

In general, then, many things can happen if there is an overlap and the initial position of the economy is inside it. About all that we can usefully say is that when there is an overlap the economy must eventually go to one equilibrium or the other, but that self-fulfilling expectations can lead it in either direction ${ }^{5}$.

What is clear from the analysis, however, is that the basic question of the respective roles of history and expectations resolves itself in this model into the question of the overlap: does an overlap exist, and how wide is it?

\section{Existence and size of the overlap}

${ }^{5}$ It would be appealing to assume that the economy must follow the shortest route to whichever equilibrium it eventually reaches, which would mean that only the outer parts of the spirals would be relevant. Unfortunately, there does not seem to be anything compeliing in the economics to require this. One may conjecture, however, that there is a maximum length of time taken to reach equilibrium, which depends on how close $L_{X}$ is to $L_{X}^{*}$. 
If there is no overlap, then history is always decisive in this model. If there is an overlap, history determines the outcome if $I_{X}$ lies outside the overlap, but expectations decide the outcome if $\mathrm{L}_{X}$ lies inside. So we must be interested in the factors determining the existence and width of the overhang.

Fortunately, the existence of an overlap depends on only three parameters: the interest rate $r, \beta$, which represents the strength of the external economies, and $\gamma$, which measures speed of adjustment. An overlap exists if and only if $r^{2}<4 \beta \gamma$.

What we see immediately is that there will be no overlap, and history will dominate expectations, if $r$ is sufficiently large. This makes sense: if the future is heavily discounted, individuals will not care much about the future actions of other individuals, and this will eliminate the possibility of self-fulfilling prophecies, We also see that a small $\beta$ eliminates the possibility of self-fulfilling expectations, because if external economies are small there will not be enough interdependence among decisions. Finally, and perhaps most interestingly, if $\gamma$ is small, so that the economy adjusts slowly, then history is always decisive. The logic here is that if adjustment is slow, factor rewards will be near current levels for a long time whatever the expectations, so that factor reallocation always follows current returns.

We might also expect that the same factors will determine the width of 
the overlap. Determining the width of the overlap explicitly, even in the linear case, is an algebraic nightmare, but the effect of $\gamma$ on the width of the overlap may be demonstrated using a simple geometric argument. In Figure 4, we show the outermost part of a spiral converging to $E_{X}$. The point $A$ on this spiral where it crosses $q=0$ determines the lower boundary of the overlap. Now suppose that we were to increase' $\gamma$. This would leave equation (8), determining the rate of change of $q$, unchanged for any given $I_{X}$ and $q$. However, at any positive $q$ the rate at which $L_{X}$ rises would be increased. So a path starting at point A would start to diverge to the right of the original path leading to $E_{X}$, and would do so increasingly over time. Clearly, in order to reach $E_{X}$ with a higher $\gamma$ we would have to start somewhere further to the left, say at $A^{\prime}$. This would then mean that the range of $I_{X}$ from which it is possible to reach $\mathrm{E}_{\mathrm{X}}$ would be wider. A corresponding argument will show that the upper boundary of the overlap will also be increased.

This should not be surprising. We noted at the beginning of this paper that in the absence of adjustment costs history is irrelevant: any equilibrium can be reached through convergent expectations. We now see that the slower the rate at which the economy adjusts, the more likely it is that history matters; if adjustment is slow enough, history is always decisive.

Figure 5 shows the results of explicit calculation of the overlap for a particular numerical example. In this example, $\mathrm{L}_{\mathrm{X}}^{*}=0.5, \beta=1, r=.1$. The width of the overlap is then calculated for various values of $\gamma$. Note that at 
$\gamma=.0025$ the overlap would disappear, while at sufficiently high levels of $\gamma$ the overlap would expand to fill the entire space, eliminating any role for history.

\section{Conclusions}

This paper has used a simple model to try to shed some light on a deep subject. As economists grow more willing to make use of models in which there are important multiple equilibria, they will have to take a position on what determines the choice of equilibrium. Most economists who have thought about it at all have assumed that history dictates the choice; but there is a counter-tradition, significantly represented in recent work, that emphasizes self-fulfilling expectations instead. There is not to my knowledge any systematic discussion of when which view is right.

What this paper has shown in the context of a simple model is that the relative importance of history and expectations depends on the underlying structure of the economy -- in particular, on the costs of adjustment. The insights gained from this analysis look as though they may be capable of considerable generalization. The methods also yield some surprising and interesting results. It is to be hoped that as the study of models with increasing returns continues to grow more important, the insights and method presented here will turn out to be useful. 


\section{REFERENCES}

Arthur,B. (1986): "Industry location patterns and the importance of history", Center for Economic Policy Research (Stanford) paper $\$ 84$.

Chacoliades, M. (1978): International Trade Theory and Policv, New York: McGraw-Hill.

David, P. (1985): "Clio and the economics of QWERTY", American Economic Review $75,332-37$.

Diamond, P. and Fudenberg, D. (1987): "Rational-expectations business cycles in search equilibrium", mimeo, MIT.

Ethier, W. (1982a): "Decreasing costs in international trade and Frank Graham's argument for protection", Econometrica 50, 1243-68.

Ethier, W. (1982b): "National and international returns to scale in the modern theory of international trade", American Economic Review 72, 389-405.

Farell, J. and Saloner, G. (1986): "Installed base and compatibility: 
innovation, product preamouncements, and predation", American Economic Review 76, 940-955.

Graham,F. (1923): "Some aspects of protection further considered", Quarterly Journal of Economics 37: 199-227.

Howitt, P. and McAfee, R.P. (1988): "Stability of equilibria with externalities", Quarterly Journal of Economics 103, 261-278.

Kaldor, N. (1972): "The irrelevance of equilibrium economics", Economic Journa1 $82,1237-55$.

Krugman, P. (1981): "Trade, accumulation, and uneven development", $\underline{\text { Journal }}$ of Development Economics 8, $149-161$.

Krugman, P. (1987): "The narrow moving band, the Dutch disease, and the competitive consequences of Mrs. Thatcher: notes on trade in the presence of dynamic economies of scale", Journal of Development Economics 27, 41-55.

Matthew, R.C.O. (1949): "Reciprocal demand and increasing returns", Review of Economic Studies $32,144 \cdot 58$. 
Matsuyama, K. (1988): "A theory of sectoral adjustment", Northwestern University discussion paper $\$ 812$.

Matsuyama, K. (1989): "Ircreasing returns, industrialization and indeterminacy of equilibrium in a perfect foresight model", mimeo, Northwestern University.

Murphy, K., Shleifer, A. and Vishny, R. (1988): "Industrialization and the Big Push", mimeo, University of Chicago.

Mussa, M. (1978): "Dynamic adjustment in the Heckscher-Ohlin-Samuelson model", Journal of Political Economy $86,775-91$.

Myrda1, G. (1957): Economic theory and underdeveloped regions, London: Duckworth.

Neary, J.P. (1978): "Dynamic stability and the theory of factor market distortions", American Economic Review 68, 671-682.

Panagariya, A. (1986): "Increasing returns, dynamic stability, anci international trade", Journal of International Economics 20, 43-63.

Romer, P. (1986a): "Increasing returns and long-run growth", Journal of 
Political Economy $94,1002-38$.

Romer, P. (1986b): "Increasing returns, specialization, and external economies: growth as described by Allyn Young", mimeo, Chicago.

Rosenstein-Rodan, P. (1943): "Problems of industrialization of Eastern and South-eastern Europe", Economic Journa1 53, 202-11.

Young, A. (1928): "Increasing returns and economic progress", Economic Journal $38,527-42$. 


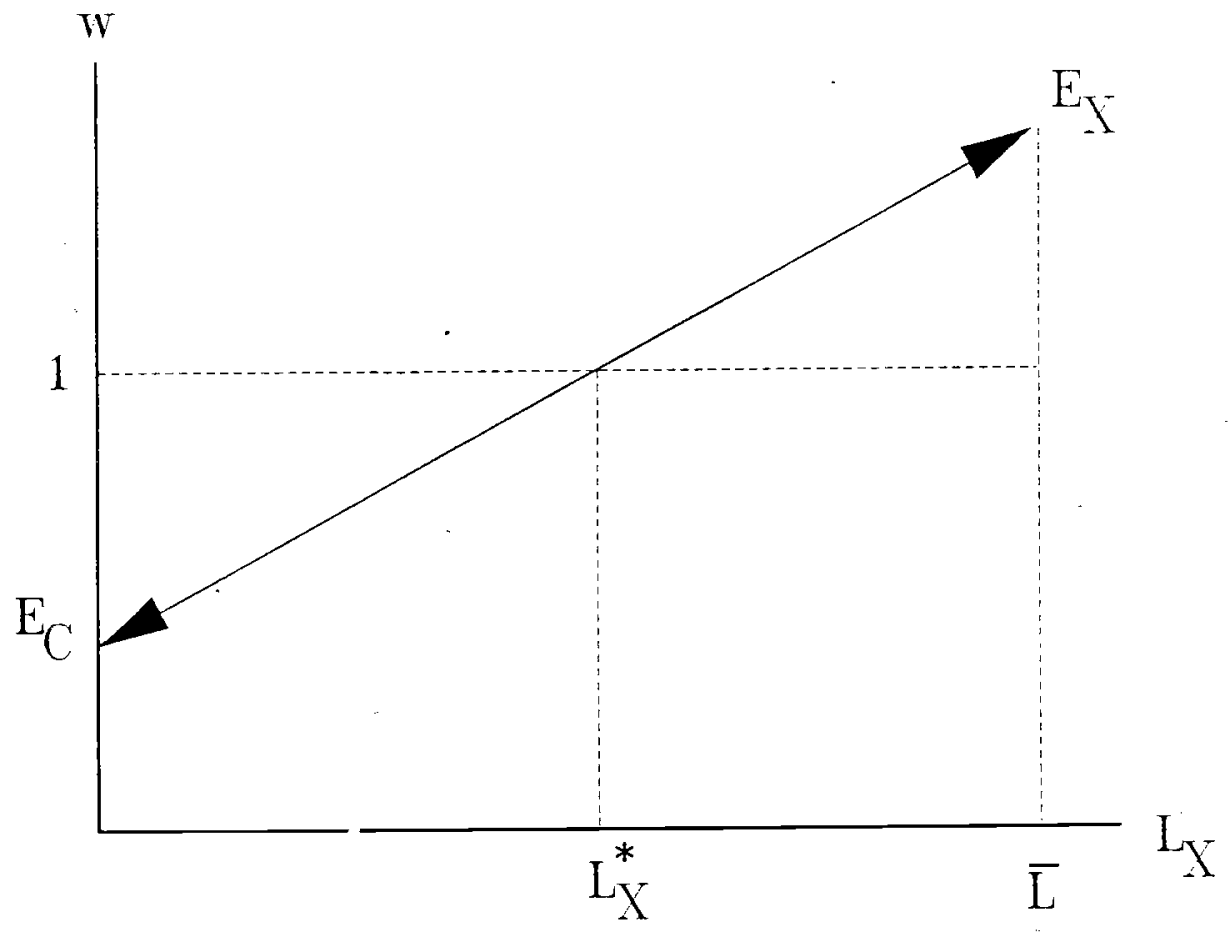

FIGURE 1 


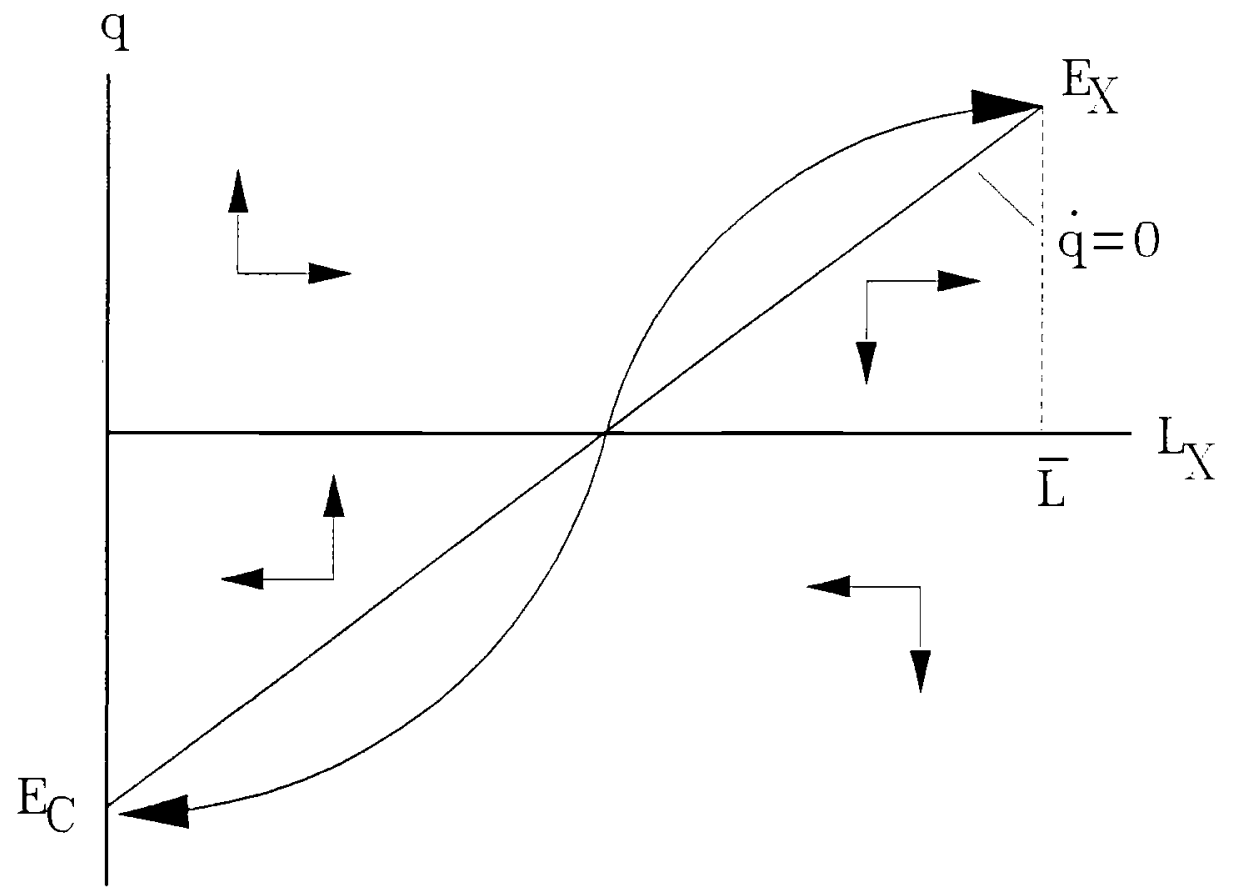

FIGURE 2 


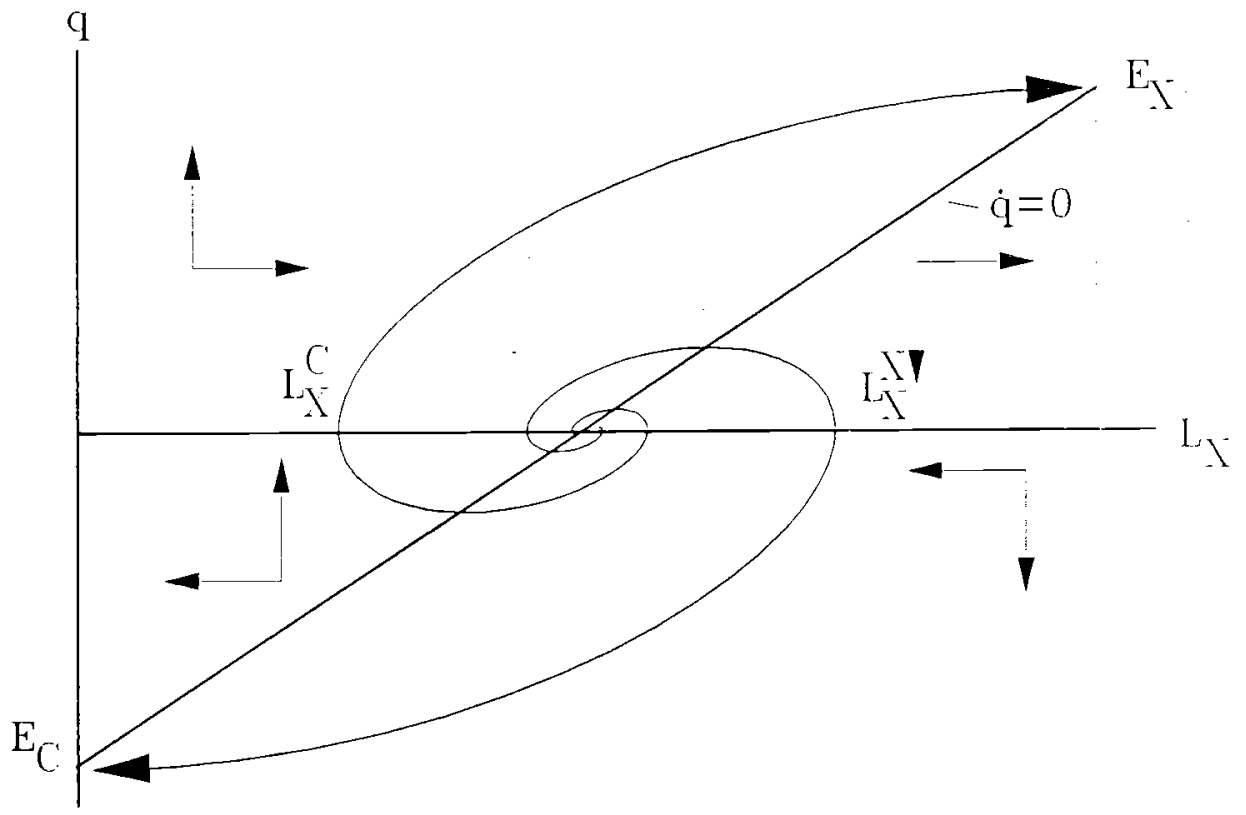

FIGURE 3 


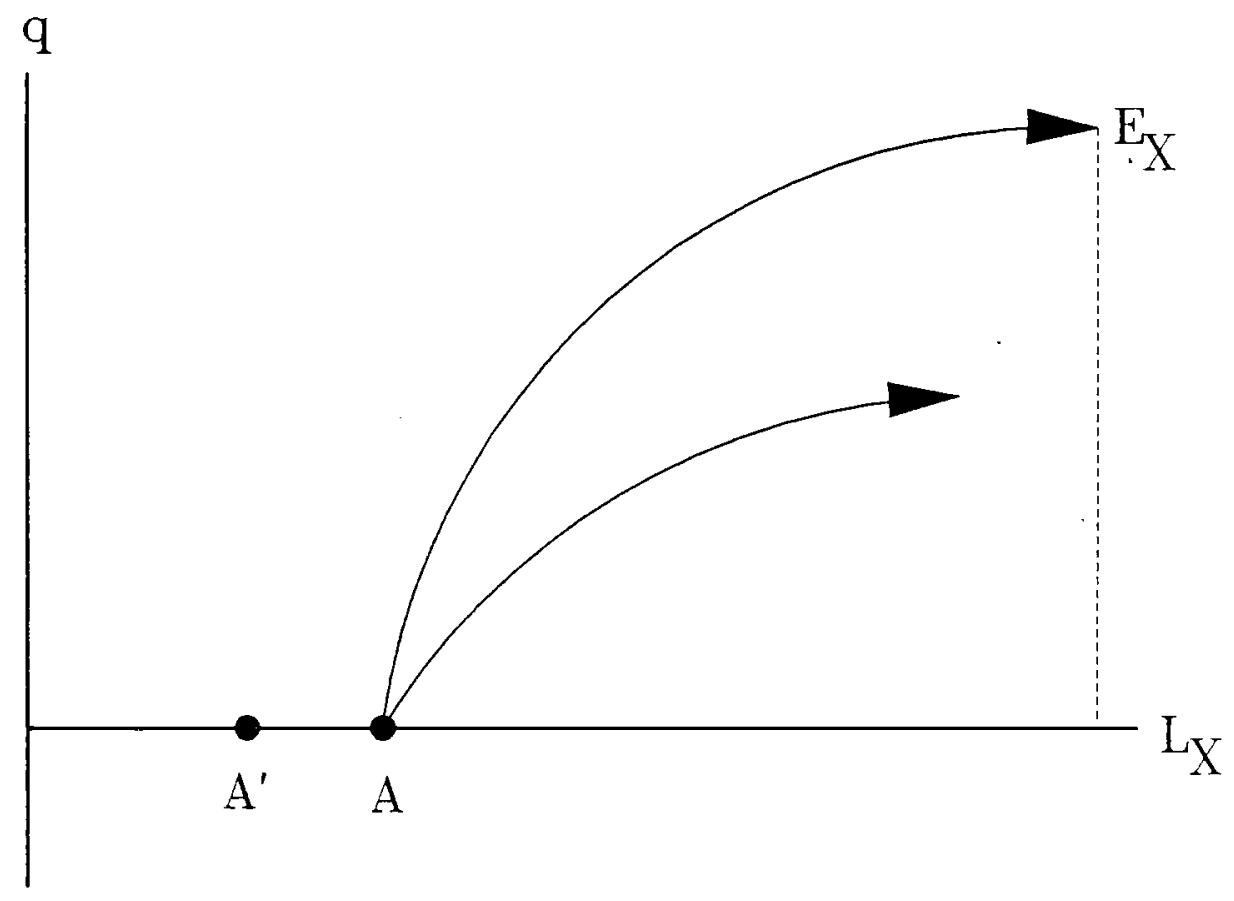

FIGURE 4 


\section{FIGURE 5}

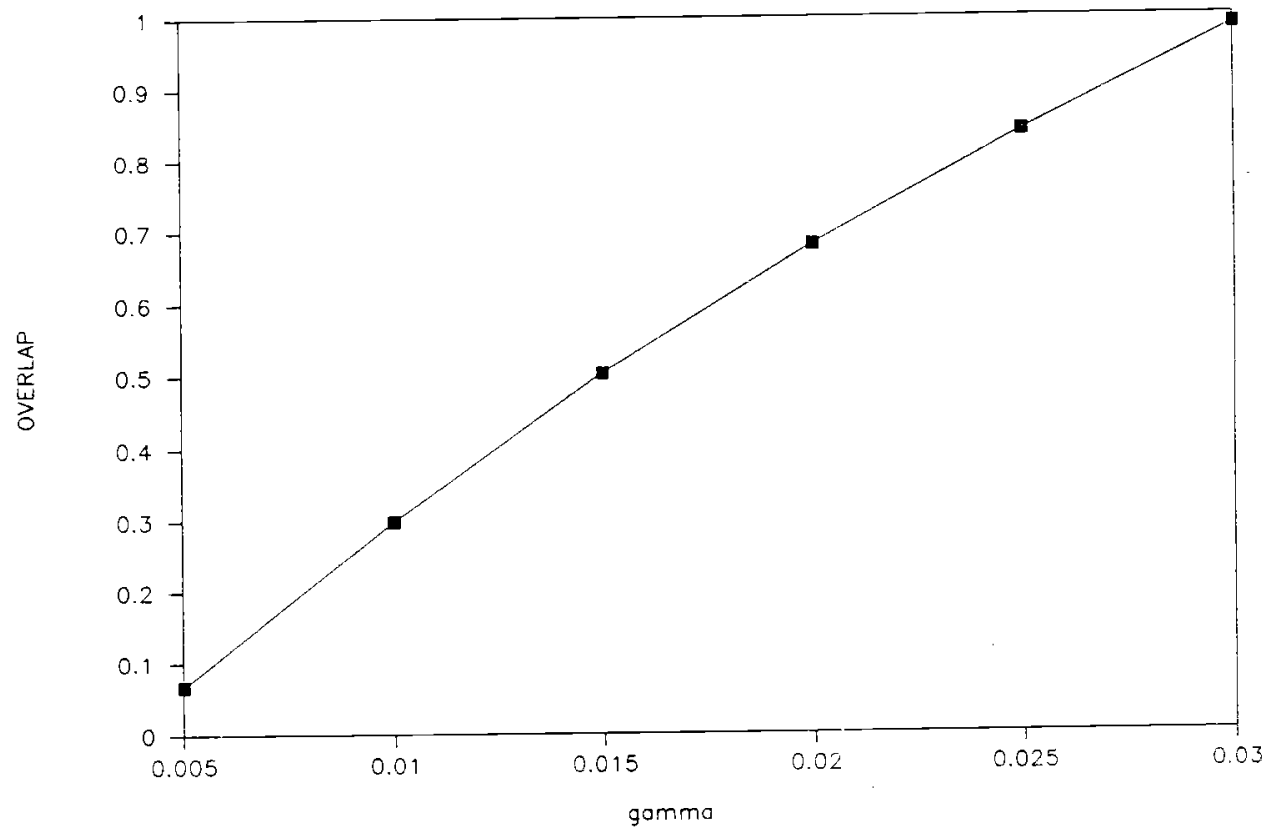

